\title{
Vertebrate Subfossil Localities in Taylorsville MetroPark, Montgomery County, Ohio, USA
}

RYAN SHELL' ${ }^{1}$ and KRISTIN ZIMMERMAN, Department of Earth and Environmental Sciences, Wright State University, Dayton, OH, USA; DAVID PETERMAN, Department of Geology and Geophysics, University of Utah, Salt Lake City, UT, USA; CHARLES CIAMPAGLIO and LAUREN FUELLING, Department of Earth and Environmental Sciences, Lake Campus, Wright State University, Celina, OH, USA; and STEPHEN J. JACQUEMIN, Department of Biological Sciences, Lake Campus, Wright State University, Celina, $\mathrm{OH}$, USA.

ABSTRACT. Karst features in the Silurian dolomites of Taylorsville MetroPark (Dayton Metropolitan Area, Ohio, United States) were explored from 2017 to 2018 to identify sites of paleontological interest. Initial landscape surveys recovered 124 skeletal elements (from 12 sites) that were attributed to 17 vertebrate species-including evidence of such extirpated animals as bobcats (Lynx rufus) and rattlesnakes (Crotalus sp.). Of the 12 sites, 9 sites contained remains from the historical era and 3 sites contained much older remains $(n=17)$ that were radiocarbon dated to approximately 1,400 years before present (YBP). Human remains at one site, butchered bones at another, and artifacts from a third suggest a long period of pre-colonial human use of the area. The presence of rare taxa expands pre-historical species lists and confirms the coexistence of many previously undocumented taxa from the area during the late, pre-colonial, Holocene Epoch.

Publication Date: December 2021

https://doi.org/10.18061/ojs.v121i2.8277

OHIO J SCI 121(2):78-89

\section{INTRODUCTION}

Taylorsville MetroPark is a part of the Five Rivers MetroParks, created in 1963 to provide outdoor recreational opportunities to the city of Dayton, Ohio, and surrounding communities. The boundaries of Taylorsville MetroPark straddle the Great Miami River and contain several bluffs on the east and west sides of the north-south trending river valley. The ledges of these bluffs are composed of the Silurian Springfield and Cedarville Dolomites and occasional outcrops of Massie Shale (ODGS 2006). The dolomites in the park (similar to other exposures in the state) weather and create karst features such as overhangs and crevices which have allowed habitation by animals, and eventual deposition of their remains, over a broad range of time (Spurlock et al. 2006). The accumulation of sediment and remains in karst features probably began in the region during the late Pleistocene and continues today, a trend that persists in other caves in the state (Spurlock et al. 2006).

The natural history of the Dayton area-based on fossils recovered in the vicinity-dates to the Paleozoic Era, as sedimentary rocks deposited from that interval make up the entirety of the bedrock

\footnotetext{
${ }^{1}$ Address correspondence to Ryan Shell, Department of Earth and Environmental Sciences, Wright State University, 3640 Colonel Glenn Hwy., Dayton, OH 45435, USA. Email: ryanshell501@gmail.com
}

that underlies the glacial deposits (ODGS 2006). These glacial and proglacial deposits preserve examples of typical late Pleistocene vertebrates, such as mammoths (Mammuthus), ground sloths (Megalonyx), giant beavers (Castoroides), large cervids (Cervalces), and bears (Ursus), as well as smaller mammals, throughout western and southwestern Ohio (Miller 1899; Mills and Guilday 1972). However, almost no examples (save for Mammuthus) of this fauna are confirmed from the Dayton area (Hansen 1992). The processes of formation and deposition of soils and alluvial sediments, common to the Dayton area today, began during the subsequent Holocene Epoch. Pre-colonial faunas from Holocene sediments in the Dayton area have not been explored. But many mammal species which have since become extinct or extirpated from the region are suspected to have existed in the Ohio River Valley-such as the bison (Bison bison), gray wolf (Canis lupus), bobcat (Lynx rufus), Passenger Pigeon (Ectopistes migratorius), and Carolina Parakeet (Conuropsis carolinensis) based on surveys from other areas (Hornaday 1887; Parmalee et al. 1978; Gibbs et al. 2001; Feldhamer et al. 2003; Fuller 2014; Toft and Wright 2015).

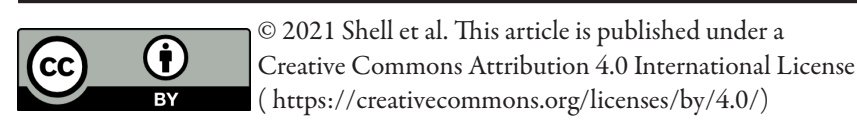


The shift in faunal composition-including extinctions and extirpations of Holocenevertebrates in the recent history of Ohio-was caused by anthropogenic habitat alterations, resource use, and introduction of new species such as the coyote (Canis latrans) and the European Starling (Sturnus vulgaris). This shift began around the time of European settlement in the region, persisting throughout much of the historical period (Gup 1990; Weeks et al. 1990). While records of these changes exist, there is little subfossil record of the vertebrate fauna present in the pre-colonial Holocene of the Dayton area or much of Ohio. Thus, the objective of this investigation was threefold: (1) to locate and inventory paleontological resources in Taylorsville MetroPark, (2) to recover a material record of this fauna, and (3) to provide systematic descriptions as an aid to future paleontological and archeological investigations in the Dayton area and surrounding region.

\section{METHODS AND MATERIALS}

Thirty survey visits to Taylorsville MetroPark were made following the acquisition of a 12-month research permit (\#RE4110.17) from the Five Rivers MetroParks. Sites were named in order of their discovery and referred to by an abbreviation of the closest trail system or landmark: Orange Trail (OT), Green Trail (GT), and Sunderland Falls (SF) (Fig. 1). During these visits, sediments under rock exposures were searched and dry sifted at mesh sizes of $2 \mathrm{~mm}$ and $1 \mathrm{~mm}$ to ensure the collection of smaller vertebrate remains. These remains were then collected, identified, and catalogued.

Because this was not an archeological study, any human artifacts were only surface-collected to preserve them for future archaeological studies. Additionally, any bone or artifact of archeological significance (or suspected to be the result of criminal activity) was reported to park administrators. Vertebrate specimens of archeological and paleontological significance are systematically described and identified, below, primarily on the basis of comparison to material housed in research collections at Michigan State University and the University of Miami. Specimens were then deposited in research collections at the Wright State University Paleontological Collections, Celina, Ohio, United States (WSU) and the Daniel Fisk Museum of Natural History, Hillsdale College, Hillsdale, Michigan, United States (DMF). Imaging of specimens in the lab was carried out using a Nikon ${ }^{\circledast}$ D7100 DSLR camera with a standard lens kit, as well as smaller Nikon handheld digital cameras.

Radiocarbon dating and pollen analysis were used to accurately estimate the ages of material recovered during the survey. Radiocarbon dating used samples from fragments of bone from sites SF001, OT001, and OT003 which were recovered and sent to DirectAMS, Bothell, Washington, for analysis following Longin (1971). Collagen was extracted from the samples and measurements of the ratios of ${ }^{14} \mathrm{C}$ in the collagen were used to calculate an uncalibrated age of the collagen in years before present (YBP). These uncalibrated ages were then used as an estimate for other material from the same layer as bones from sites listed above.

Pollen analysis compared pollen grains found in the sediments containing bone elements to known lake cores from nearby Silver Lake (Logan County, Ohio) (Ogden 1966) and Crystal Lake (see below). Pollen analysis was done by measuring approximately $10 \mathrm{ml}$ samples of sediment in beakers and adding $1 \mathrm{M}$ hydrochloric acid $(\mathrm{HCl})$. Sediment was then boiled in $\mathrm{HCl}$ for 30 to 40 minutes to remove non-pollen material. $\mathrm{HCl}$ was chosen because sediments associated with karst features are derived from Silurian dolomite (Cedarville and Springfield Formations) and this acid was needed to dissolve excess carbonate minerals from the sample. After allowing the sediment to cool, the samples were wet sieved through $124 \mu \mathrm{m}$ and $74 \mu \mathrm{m}$ sieves. The samples dried for at least 6 hours before continued analysis. Smear slides of the sieved material were used to conduct light-microscopy pollen analysis as described in Moore et al. (1991). The slides were scanned at $400 \times$ magnification and any pollen taxa were documented. Many soil samples taken for pollen analysis failed to provide adequate numbers (usually 500 to 1,000 per sample required) of pollen grains for what would typically be considered an "in-depth" analysis of each site (Moore et al. 1991; Taylor et al. 2009). Furthermore, the sediment itself was from a terrestrial deposit; counting the exact percentage of each taxon from such a small sample would not provide an accurate representation of regional vegetation, as terrestrial sediment does not provide a sufficiently rich, unbroken, or undisturbed record of geologic time (Moore et al. 1991). Thus, relative age estimations based on pollen from the colluvium of these sites were deemed less accurate than radiocarbon dates. 


\section{RESULTS}

\section{General Paleontological and Site Descriptions}

A total of 124 skeletal elements, representing 17 unequivocal taxa, were recovered from 12 sites in Taylorsville MetroPark. Additionally, a few recent partial skeletons of white-tailed deer were found at a dump site and left in the park as potential evidence of poaching. Human bones deemed historical or archeological in nature were taken to the Montgomery County, Ohio, Coroner's office for testing, and eventual reburial, per Ohio state law.
While human remains were recovered from a single site (SF001), no artifacts were found in association with the remains.

Mammals were by far the most common recovered specimens. Of these, the raccoon (Procyon lotor) was the most common mammal, with remains spanning almost every subfossil site in the park. The eastern cottontail rabbit (Sylvilagus floridanus) (3), whitetailed deer (Odocoileus virginianus) (4), red fox (Vulpes vulpes) (2), and other unknown mammals all appeared more than once in the subfossil record in

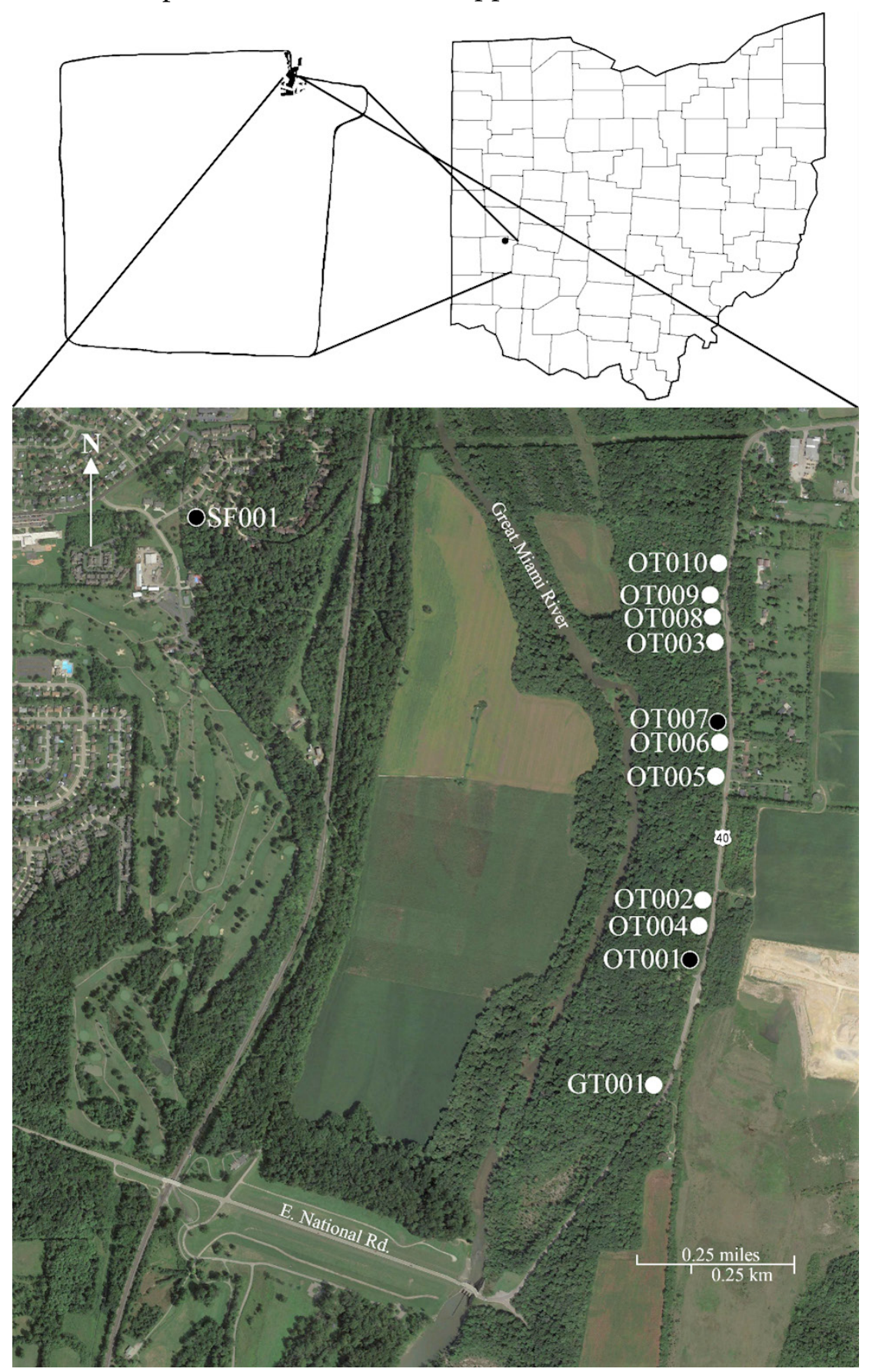

FIGURE 1. Location map of all vertebrate subfossil producing sites within Taylorsville MetroPark, situated within the boundaries of Montgomery County and the state of Ohio. Localities with white dots are estimated to be sites of modern deposition, while localities with black dots are estimated to be from the late Holocene prior to the historical period. 
the area (Table). White-tailed deer and eastern gray squirrels (Sciurus carolinensis) tied as the second most abundant mammal in terms of number of remains. Other species were rare, occurring only once in the area. The cause of this rarity may have been a product of behavior, competition, or preservation factors. These mammals include the groundhog (Marmota monax) and an unknown canid.

In addition to mammals, several elements from reptiles were found-with 2 examples of a single species of Rattlesnake (Crotalus sp.) and 1 Garter Snake (Thamnophis sp.) recorded from 2 sites in the park (OT003 and SF001). Both the fossil records of Crotalus and Thamnophis in the state have a gap spanning the entire Holocene Epoch, and while members of the genus Thamnophis are present in most of Ohio today, the genus Crotalus has been extirpated from much of the state (Holman 2000). Lastly, a number of unidentifiable elements (3) from birds were also recovered (referred to herein as Aves indet.).

Of the 12 sites recorded, 8 were judged to be very recent because of both their preservation quality and the species content being reflective of the current fauna. The other 4 were judged to be older due to their species content (OT003, SF001), degree of preservation (OT007), or associated artifacts (OT001). Radiocarbon dating further narrowed this number of pre-historic sites to just 3, as remains from OT003 were dated to the historical period $(146 \pm 22 \mathrm{YBP})$.
Site OT001 was located south of a large outcrop with exposed dolomite and travertine. Near the top of a slope, the astragalus of an eastern cottontail rabbit (S. floridanus) (DMF 4883) was recovered from the surface and determined to be of recent origin based on its preservation quality. Underlying this, at approximately $3 \mathrm{~cm}$ in sediment depth, an older mandible fragment from a raccoon (DMF 4882) was found which displayed a possible cut mark on the proximal end-near where the ascending ramus would have been. Farther down the slope, a fragment of a chert projectile point (DMF 4880) (Fig. 2) was recovered. Because of the thickness of the projectile point, it is more likely the point of a spear or atlatl dart which required larger projectile points than arrows (Werner and Willoughby 2018). As the arrow replaced the atlatl in the Ohio River Valley around 1,500 YBP, this time provides a reasonable estimate for the youngest possible age of the tool at this site.

Site OT007 is a small debris cone, eroding out from a crevice in a dolomite wall. In the sediment, remains of a white-tailed deer (DMF 4889 to 4890), and an eastern gray squirrel (DMF 4891) were recovered. Pollen grains from OT007 were rare and only maple (Acer sp.) were recovered. Maple pollens appeared in Crystal Lake cores around 14,000 YBP, while they seem to have appeared in cores from Silver Lake around 9,000 YBP (Ogden 1966; Kopera 2018; Kopera and Teed 2019). While maples are still a major component of forests around

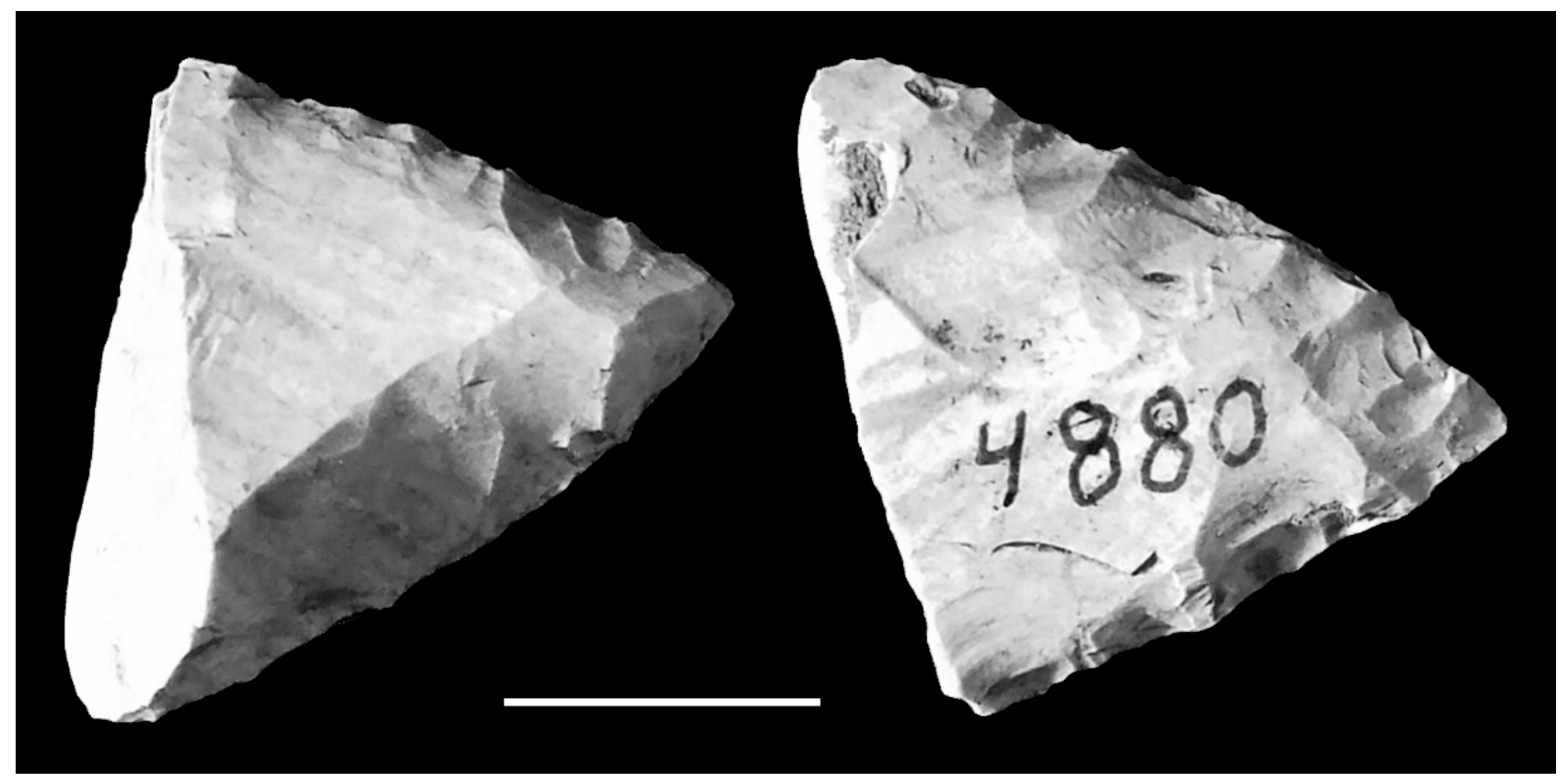

FIGURE 2. Partial chert projectile point (DMF 4880) recovered from OT001 (scale bar $=1 \mathrm{~cm}$ ) 
Table

Inventory of subfossils and localities

\begin{tabular}{|c|c|c|c|}
\hline \multicolumn{4}{|c|}{ Modern and historical period subfossils } \\
\hline Site & Species & Number of elements & Specimen numbers \\
\hline \multirow{2}{*}{ OT001 } & Sylvilagus floridanus & 1 & $\overline{\text { DMF } 4883}$ \\
\hline & Procyon lotor & 1 & DMF 4882 \\
\hline OT002 & P. lotor & 1 & DMF 4884 \\
\hline \multirow[t]{8}{*}{ OT003 } & Marmota monax & 1 & DMF 4930 \\
\hline & Rodentia indet. & 2 & DMF 4937-4938 \\
\hline & Lynx rufus & 2 & DMF 4931-4932 \\
\hline & S. floridanus & 33 & WSU 1452A-AG \\
\hline & Canis sp. & 1 & DMF 4926 \\
\hline & Vulpes sp. & 3 & DMF 4927-4928, 4933 \\
\hline & Crotalus sp. & 3 & DMF 4934-4936 \\
\hline & Didelphis virginiana & 1 & DMF 4929 \\
\hline OT004 & P. lotor & 3 & DMF 4886-4888 \\
\hline OT005 & S. floridanus & 1 & DMF 5825 \\
\hline OT006 & P. lotor & 2 & DMF 5827 \\
\hline OT008 & Sciurus carolinensis & 1 & DMF 5420 \\
\hline \multirow[t]{2}{*}{ OT009 } & Odocoileus virginianus & 2 & DMF 5823-5824 \\
\hline & O. virginianus & 1 & DMF 5829 \\
\hline GT001 & S. carolinensis & 1 & DMF 5822 \\
\hline \multicolumn{4}{|c|}{ Pre-colonial subfossils (and artifacts) } \\
\hline Site & Taxa or description & Number of elements & Specimen numbers \\
\hline OT001 & Projectile point fragment & 1 & $\overline{\text { DMF } 4880}$ \\
\hline \multirow[t]{2}{*}{ OT007 } & S. carolinensis & 1 & DMF 4891 \\
\hline & O. virginianus & 2 & DMF 4889-4890 \\
\hline \multirow[t]{9}{*}{ SF001 } & Aves indet. & 1 & WSU 1451 \\
\hline & Aves indet. & 1 & WSU 1450 \\
\hline & Aves indet. & 1 & WSU 1453 \\
\hline & Crotalus sp. & 1 & WSU 1492 \\
\hline & Thamnophis sp. & 1 & WSU 1491 \\
\hline & Rodentia indet. & 1 & WSU 1455 \\
\hline & Teleostei indet. & 3 & WSU 1449A-C \\
\hline & Homo sapiens & N/A & See text \\
\hline & S. carolinensis & 2 & WSU 1454A-B \\
\hline
\end{tabular}


the site, the lack of pollen grains associated with agricultural plants like corn and soybeans (Zea and Glycine respectively, which are grown very close to the park boundaries) suggests that the sediment of this site may have been deposited sometime before the modern era. A stone tool fragment (see above) was recovered from a site less than $500 \mathrm{~m}$ distant, which may suggest pre-Columbian human use of the bones recovered here.

Site SF001 is the only site discovered on the western side of the park. It is similar to OT003 in that bones are preserved in a shallow cave. The sediments at this site, however, are much drier and lack the rich organic and humic substances of those in sites from the eastern part of the park. While this site is approximately $750 \mathrm{~m}$ from any fish-producing body of water, fish bones (WSU 1449) have been found here and not at other sites. The human presence mentioned above is confirmed in SF001 by the occurrence of human bones as well. The bones found during this study were deemed historical or archeological in origin and turned over to local law enforcement agencies; they will likely be reburied on site, as they are not part of any ongoing investigation. The only pollens observed at this locality were of the genus Ulmus which seems to be exclusively Holocene in this region, as evidenced from lake cores at Crystal Lake (Kopera 2018; Kopera and Teed 2019). The ${ }^{14} \mathrm{C}$ analysis, on the other hand, paints a more precise picture. A sliver of unknown bone taken from the same layer as the other finds at the site yielded an uncalibrated carbon-dated age of $1,433 \pm 27$ YBP. It would therefore seem that the human remains may be associated with the Late Woodland archeological tradition, which is part of the upper age estimation for OT001. Combining the radiocarbon date with Crystal Lake pollen data, it is suggested that most of the animals and people deposited at SF001 lived in an oak-dominated forest with occasional maple and hickory (Kopera 2018; Kopera and Teed 2019).

\section{Systematic Descriptions}

Subfossils relating the vertebrate fauna that existed in Ohio prior to European colonization were the primary interest of this investigation. These subfossils are described systematically below.

\section{Taxonomy:}

Phylum Chordata Haeckel, 1874

Class Actinopterygii Klein, 1885

Infraclass Teleostei Muller, 1845

Species Teleostei indet.

Material: WSU 1449 A-C (Fig. 3E): Vertebrae and 1 possible operculum fragment.

Description: The material referred to in this group consists of 2 vertebrae (with diameters of $1 \mathrm{~mm}$ and $0.5 \mathrm{~mm}$ ) and a long, flat bone which, while fragmented, likely represents the opercular cover of a fish's gill system.

Notes: The vertebrae themselves are the most diagnostic elements of this group: the anterior and posterior faces of each of the centra are concave-a condition only found in aquatic vertebrates, especially bony fishes. Additional evidence of paired dorsal and ventral projections on each vertebra, combined with the spongy histology of each, excludes vertebrates such as birds, amphibians, reptiles, or any other vertebrate to which a $1 \mathrm{~mm}$ centrum could correspond. Furthermore, the site in which these remains were recovered, SF001, contained a sample which was radiocarbon dated to approximately $1,400 \mathrm{YBP}$, suggesting that these teleost fishes were part of a fauna similar to that of the present day.

The taphonomy of these fish remains is somewhat unclear, given that SF001 is approximately $750 \mathrm{~m}$ from any nearby water source capable of sustaining fishes. However, a number of other animals have been recovered from SF001, some of which may have preyed upon small fishes. It is therefore possible that these remains were deposited at this locality as excrement, as discarded refuse by predators and scavengers that were alive at the time of deposition, or as stomach contents of a dead piscivorous predator or scavenger that has since been disarticulated by weathering processes. 


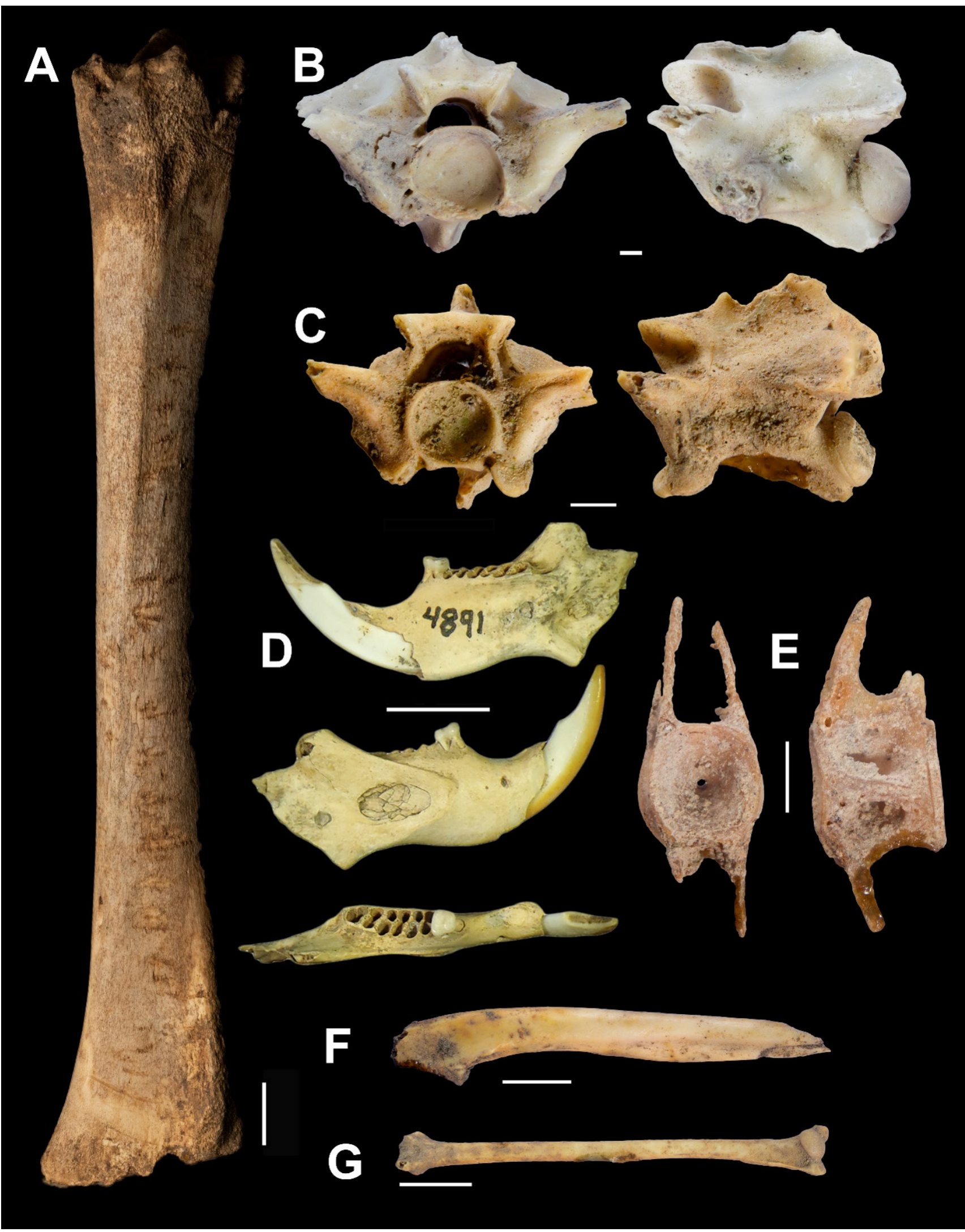

FIGURE 3. Specimens of note from the Holocene of Taylorsville MetroPark: (A) DMF 4889 tibia belonging to the whitetailed deer (Odocoileus virginianus) displaying cut marks on the posterior surface, scale bar $=1.0 \mathrm{~cm}$; (B) WSU 1492 anterior and lateral views of rattlesnake (Crotalus sp.) vertebra, scale bar $=1.0 \mathrm{~mm}$; (C) WSU 1491 anterior and lateral views of garter snake (Thamnophis sp.) vertebra, scale bar = 1.0 mm; (D) DMF 4891 lateral and occlusal views of eastern gray squirrel (Sciurus carolinensis) mandible, scale bar $=5.0 \mathrm{~mm}$; (E) WSU 1449A anterior and lateral views of an unknown teleost vertebra, scale bar= $1.0 \mathrm{~mm}$; (F) WSU 1455 fragmentary long bone (possibly an ulna) of an unknown rodent, scale bar=5.0 mm; (G) WSU 1451 long bone from an unknown, probably passerine, bird, scale bar $=5.0 \mathrm{~mm}$ 


\section{Taxonomy:}

Class Reptilia Laurenti, 1768

Order Squamata Oppel, 1811

Family Viperidae Oppel, 1811

Genus Crotalus Linnaeus, 1758

Species Crotalus sp. (Rattlesnake)

Material: DMF 4934-4936, WSU 1492: thoracic vertebrae (Fig. 3B).

Description: The thoracic vertebrae recovered during this study are all fairly short and wide. The articular surface is convex on the posterior (the cotyle) and concave on the anterior (the condyle). Many of the projections of the neural arch are eroded; however, all examples preserve a hypapophysis on the ventral surface that is posteroventrally oriented (though also worn). The spinous process is fairly short, and the postzygapophyseal articular facets flare out somewhat from the axis of each bone.

Notes: The short and wide overall shape of these vertebrae, coupled with fairly thick spine-like, posteroventrally oriented hypapophyses confirms the viperid affinity of these vertebrae. Though the hypapophysis in the specimens recovered are broken distally, enough detail remains for comparison (Meylan 1982; Holman 2000). Further assignment of these specimens to Crotalus is based on comparison to specimens GDF 135-7 (housed at the University of Miami), in addition to specimens MSUM-SH 1701, MSUM-SH 2375, MSUM-SH 1727, and MSUM-SH 1853 (all housed at Michigan State University and figured in Holman (2000)).

Vertebral remains of this genus can be difficult to distinguish from one another (Holman 2000). One of the exceptions to this observation is the difference between the Timber Rattlesnake (Crotalus horridus), and the Eastern Diamondback Rattlesnake ( $C$. adamanteus). Vertebra from $C$. horridus have higher neural spines than those of the $C$. adamanteus (Holman 2000). C. horridus is still present in Ohio, and these specimens do have fairly low neural spines (Holman 2000). The spines (on the recovered specimens) appear worn on the dorsal surface, however, so while the identity of the Crotalus species from these sites is likely $C$. horridus, there is no way to be certain with the specimens recovered.

\section{Taxonomy:}

Family Colubridae Oppel, 1811

Genus Thamnophis Fitzinger, 1843

Species Thamnophis sp. (Garter Snake)

Material: WSU 1491: vertebra (Fig. 3C).

Description: The vertebra belonging to this genus was recovered from SF001 and displays a number of worn processes, similar to the wear seen on the Crotalus specimens.

Notes: This specimen is referred to this genus on the basis of shape: the cotyle and condyle are consistent in form with other snakes (see Crotalus), and the anterior and posterior processes project outward from the neural arch, parallel the length of the animal, and are distinctly X-shaped when viewed dorsally. This is easily comparable to specimens such as MSUM-SH 2302 (housed at Michigan State University and figured by Holman (2000)) and MSUM-SH 3056 (also figured by Holman (2000)). Additionally, the snake genera Nerodia and Thamnophis have well developed, posteriorly oriented, hypapophyses on the ventral side of the vertebrae which are pointed (Holman 2000). Thamnophis vertebrae, and this specimen in particular, can both be distinguished from Nerodia, because Thamnophis vertebrae have a longer length relative to their height (Holman 2000).

Radiocarbon dating from SF001 produced an uncalibrated age of approximately 1,400 YBP, suggesting this specimen (and the rest of the vertebrate assemblage recovered here) were deposited approximately during that time. The occurrence of this snake genus at this point in the late Holocene, while unprecedented in the subfossil record, is not surprising given that Pleistocene Thamnophis fossils have been recovered from Ohio (see Holman 1995, 2000) and that the species is widespread in Ohio today.

\section{Taxonomy:}

Class Aves Linnaeus, 1758

Species Aves indet.

Material: WSU 1450, 1451 (Fig. 3G), 1453: long bones.

Description and notes: The bones referred to unknown (possibly passerine) birds in this study and were all recovered from SF001. They are all small, thin-walled, and hollow: features indicative of flying birds. 


\section{Taxonomy:}

Class Mammalia Linnaeus, 1758

Infraclass Eutheria Gill, 1872

Order Rodentia Bowdich, 1821

Species Rodentia indet.

Material: WSU 1455 (Fig. 3F), DMF 4937 and 4938: fragmentary long bones.

Description and notes: The bones assigned to this taxon were recovered from OT003 (DMF 4937 and 4938) and SF00 1 (WSU 1455), meaning they range in age over approximately the last 1,500 years. The bones are all small, heavily worn, and fragmented. Birds and rodents are both able to produce bones of this size; however, the lack of hollow spacing in this material eliminates the possibility that these are bird remains.

\section{Taxonomy:}

Family Sciuridae Fischer de Waldheim, 1817

Genus Sciurus Linnaeus, 1758

Species Sciurus carolinensis Gmelin, 1788

(eastern gray squirrel)

Material: DMF 4891: Mandible (Fig. 3D). DMF 5420: cranium, additional long bones. WSU 1454 A-B.

Description: Long bones recovered during this investigation are worn. Many have missing articulation sites on the distal or proximal end. Two specimens, however, are of greater diagnostic use: the mandible DMF 4891 from OT007 and the cranium DMF 5420 from OT008 (a modern site).

DMF 4891 is a right mandible that is fairly well preserved, especially on the anterior. The incisor and premolar are in place; however, all subsequent molars are missing. The most posterior portion of the bone has also been weathered, meaning both part of the ascending ramus and condyle are absent in this specimen. The outward facing surface of the bone has a pair of damaged areas, which could have been made by the teeth of a predator or scavenger.

DMF 5420 is a modern specimen. The ventral surface of the skull is well preserved with both incisors-and 3 of the original 6 molars-still in place, though the anterior-most portion of the maxilla is worn away. The posterior zygomatic arches are missing on both sides, but there is enough of the anterior zygomatic region to note the classic sciuromorphan morphology indicative of this family. The parietal bone on the right side is partially missing, exposing the brain case.
Notes: Despite deposition from different times and at different sites, the mandible, DMF 4891, corresponds well to the cranium, DMF 5420, suggesting that both specimens belong to the same species. Furthermore, these remains correspond well to studies on modern eastern gray squirrels, such as the work of Velhagen and Roth (1997), leaving the identity of the mandible DMF 4891 well beyond a reasonable doubt. The long bones, however, can only be tentatively assigned to this species; they fit the likely characteristics for rodent bones (see above), but are generally too large to suggest an affinity with mice or voles. Remains from this species could suggest that members of $S$. carolinensis in this region were present throughout much of the late Holocene, though this record is unsurprising considering the common appearance of squirrel remains in archeological sites spanning the Holocene (Spurlock et al. 2006).

\section{Taxonomy:}

Order Artiodactyla Owen, 1848

Family Cervidae Goldfuss, 1820

Genus Odocoileus Rafinesque, 1832

Species Odocoileus virginianus

(Zimmermann, 1780) (white-tailed deer)

Material: DMF 4889 - 4890: tibia (Fig. 3A) and associated unidentified long bone.

Description: The tibia recovered from OT007 is worn on the proximal end, though it still presents a triangular cross section. The distal articulation surface contains a series of facets for articulation with tarsal bones. The proximal lateral facet, which projects outward from the distal articulation surface, joins the body of the bone at a steep angle. The surface of the bone is covered in a number of abrasions interpreted as cut marks from a manmade tool. The associated long bone was heavily weathered on both the proximal and distal ends.

Notes: The tibia (DMF 4889) of this animal provided the most diagnostic information. The proximal articulation site of this specimen is triangular in overall shape, which is consistent with descriptions by Rumph (1975). However, weathering obscures additional information. The distal articulation surface is concave and also possesses the overall shape and structures described by Rumph (1975). The steep angle at which the proximal lateral facet connects to the rest of the distal articulation surface differentiates this animal 
from other members of its genus such as the mule deer (Odocoileus hemionus) as described and figured by Jacobson (2004). These bones were found with what appear to be cut marks (numerous straight abrasions on the surface of the bone that do not occur in pairs, as would rodent gnaw marks) (see Spurlock et al. 2006). These imply human modification (perhaps butchering) of these bones. Other animals were found in the same site, though it was unclear whether they were also butchered. No artifacts were recovered.

\section{DISCUSSION}

The dolomite cliffs, overhangs, and caves of Taylorsville MetroPark preserve a large number of vertebrate remains. Information from these remains span much of the late Holocene and illustrate slices of life at 2 very different times for vertebrates throughout the epoch, specifically the pre-Columbian period of human occupation and the historical (or modern) era (see Fig. 4). These surveys and data help to expand the understanding of the faunal history of the state and specific region.

Most remains seem to have been deposited as the result of scavengers (Virginia opossum (Didelphis virginiana), raccoon (P. lotor)) or predators (red fox ( $V$. vulpes), bobcat (L. rufus)) which may have used the outcrops for shelter or as dens. But given the record of Native American use of the area beginning sometime before $1,400 \mathrm{YBP}$-as evidenced by OT001 and SF001 (though OT007 may also preserve a portion of this history)- some evidence may represent human-mediated deposition of faunal remains.

The shallow cut marks on the bones of the white-tailed deer (O. virginianus) show evidence of butchering (Fig. 3A). While it is unclear what tool was used to make the cuts, this occurrence expands our understanding of human activity in the area. It is likely that these bones (given their proximity) date from around the same time as the deposition of OT001: from the late Pleistocene to present day (Halligan et al. 2016).

Expanding on the understanding of the vertebrate fauna of the area, the presence of Rattlesnake (Crotalus sp.) remains in the park was surprising. One set of remains was found at SF00 1 and is approximately 1,400 years old while another (OT003) is much younger. This suggests that the genus Crotalus may have migrated into the region earlier in the Holocene (because it is unknown from Pleistocene snake faunas of the region (Holman 2000)), then persisted for thousands of years, only to die out in this region sometime after 150 YBP. Another report of rattlesnake remains dated from 1,410 \pm 60 YBP (part of the Late Woodland archeological tradition) fits well into this interpretation (Spurlock et al. 2006). The garter snake (Thamnophis sp.) has been reported in the state since the latest Pleistocene $(11,700 \pm 220 \mathrm{YBP})$ (see Holman 1995, 2000); while its fossil record in the Holocene of Ohio was non-existent prior to this study, the appearance Thamnophis sp. in the sediments of SF001 is not as surprising.

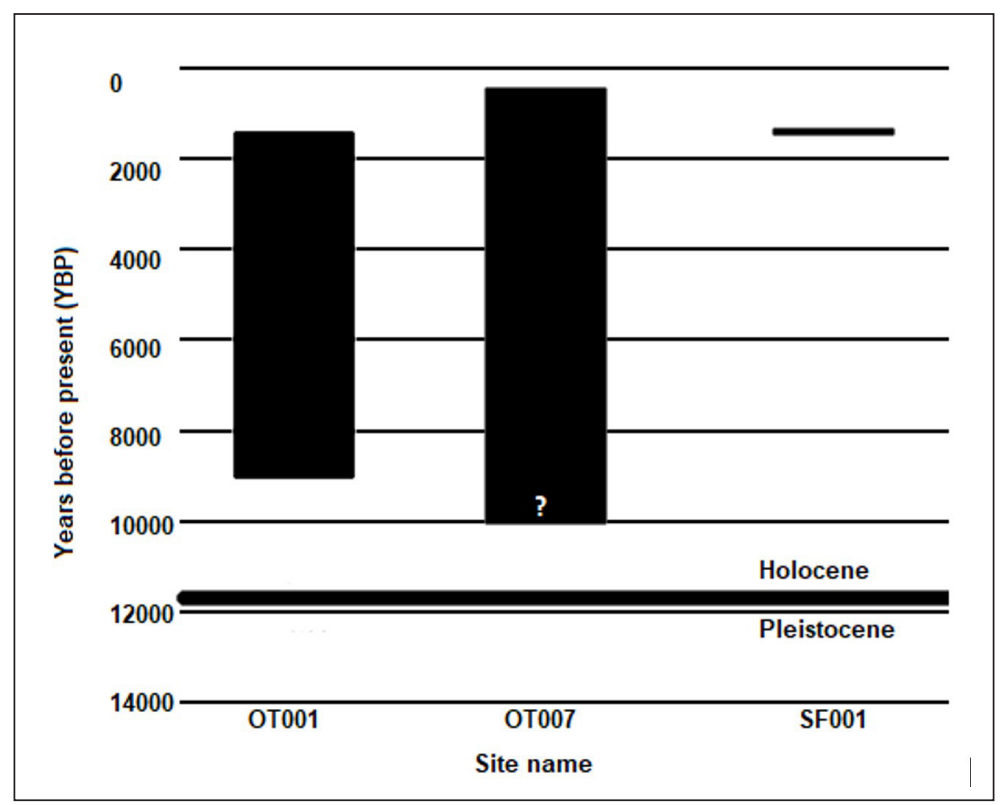

FIGURE 4. Box plot of the age-range estimations for the 3 oldest vertebrate sites in Taylorsville MetroPark, and their relative comparison to the Pleistocene-Holocene boundary (11,700 YBP) (see Cohen et al. 2020) 


\section{Conclusions}

This survey highlights the use of the Five Rivers MetroParks system as a potential source of additional localities of paleontological and archeological interest. Taylorsville MetroPark contains remains of animals that have been extirpated from the region (such as L. rufus (Table) and Crotalus sp.), sites with butchered bones, a site with a stone artifact, and a site with human remains. It is likely that additional work on Taylorsville MetroPark, and other parks in the Five Rivers MetroParks system, will continue to produce discoveries that assist in understanding the natural history of the Ohio River Valley.

\section{ACKNOWLEDGEMENTS}

The authors would like to express our thanks to the Five Rivers MetroParks system, especially Mary Klunk, for their help in the permitting and reporting process of this work. We would also like to thank Dr. Anthony Swinehart of Hillsdale College for helping us curate many of our specimens. Additionally, assistance in the field was provided by Tristian Coffee, Matthew Hoenig, Alexander Gilles, and Michael McKean. We greatly appreciate Lawrence Adrian, Amy Collette, Rachel Eastman, Vic Habersmith, Matija Mazi, Eric Walters, and the Wright State University Lake Campus Research Committee, all for their financial support for this project.

\section{LITERATURE CITED}

Cohen KM, Finney SC, Gibbard PL, Fan JX. 2020. The ICS international chronostratigraphic chart. International Commission on Stratigraphy. 1 p. https://stratigraphy.org/ICSchart/ChronostratChart2020-03.pdf

Feldhamer GA, Thompson BC, Chapman JA. 2003. Wild mammals of North America: biology, management, and conservation. Baltimore (MD): Johns Hopkins University Press. 1216 p. ISBN 13: 9780801874161.

Fuller E. 2014. The Passenger Pigeon. Princeton (NJ): Princeton University Press. Chapter 6, Extinction: the causes; p. 7089. ISBN 13: 9780691162959. https://www.jstor.org/stable/j.ctt7ztpmj

Gibbs D, Barnes E, Cox J. 2001. Pigeons and doves: a guide to the pigeons and doves of the world. New Haven (CT): Yale University Press. Section, Passenger Pigeon; p. 318, plate 27. ISBN 13: 9780300078862.

Gup T. 1990 Sep 1. 100 years of the Starling. The New York Times. Sect. 1:19.

https://www.nytimes.com/1990/09/01/opinion/100-years-of-the-starling.html
Halligan JJ, Waters MR, Perrotti A, Owens IJ, Fienberg JM, Bourne MD, Fenerty B, Winsborough B, Carlson D, Fischer DC, Stafford TW Jr, Dunbar JS. 2016. Pre-Clovis occupation 14,550 years ago at the Page-Ladson site, Florida, and the peopling of the Americas. Sci Adv. 2(5). https://doi.org/10.1126/sciadv.1600375

Hansen MC. 1992. Bestiary of Pleistocene vertebrates of Ohio. Ohio Geol. Winter:1, 3-6. A quarterly publication [newsletter] of the Ohio Department of Natural Resources, Division of Geological Survey. Publication Series: OGN 1992-WI.

https://ohiodnr.gov/static/documents/geology/OGN_1992_n3Winter.pdf

Hornaday WT. 1887. The extermination of the American bison, with a sketch of its discovery and life history. Report of [United States] National Museum [annual report]. p. 367548. Note: now the National Museum of Natural History, Smithsonian Institution, Washington, DC. https://doi.org/10.5962/bhl.title.78803

Holman JA. 1995. Pleistocene amphibians and reptiles in North America. Oxford (UK): Oxford University Press. 243 p. ISBN 13: 9780195086102.

Holman JA. 2000. Fossil snakes of North America: origin, evolution, distribution, paleoecology. Bloomington (IN): Indiana University Press. 357 p. ISBN 13: 9780253337214.

Jacobson JA. 2004. Determining human ecology on the Plains through the identification of mule deer (Odocoileus hemionus) and white-tailed deer (Odocoileus virginianus) postcranial material [PhD dissertation]. [Knoxville (TN)]: University of Tennessee.

https://trace.tennessee.edu/utk_graddiss/2264

Kopera K. 2018. Vegetation sensitivity during the Mid-Holocene warming in western Ohio. Geol Soc Am Abs Prog. 50(6) https://doi.org/10.1130/abs/2018AM-322485

Kopera K, Teed R. 2019 Mar 27. Vegetation sensitivity during the Mid-Holocene warming in western Ohio. In: Joint section meeting of the Geological Society of America: 53rd SouthCentral, 53rd North-Central, 71st Rocky Mountain; 2019 March 25-27; Manhattan (KS). Boulder (CO): Geological Society of America. 51(2):24. Session No. 38-4.

https://www.geosociety.org/documents/gsa/section/ sc/2019/2019_SC-NC-RM_Program.pdf

Longin R. 1971. New method of collagen extraction for radiocarbon dating. Nature. 230:241-242. https://doi.org/10.1038/230241a0

Meylan PA. 1982. The squamate reptiles of the Inglis IA fauna (Irvingtonian: Citrus County, Florida). Bull Fla State Mus Biol Sci. 27(3):3-85. http://purl.flvc.org/fcla/dl/UF00000976.pdf

Miller GS Jr. 1899. A new fossil bear from Ohio. Proc Biol Soc Wash. 13:53-56.

https://hdl.handle.net/2027/osu.32435065795148

Mills RS, Guilday JE. 1972. First record of Cervalces scotti Ledekker from the Pleistocene of Ohio. Am Midl Nat. 88(1):255. https://doi.org/10.2307/2424508 
Moore PD, Webb JA, Collinson ME. 1991. Pollen analysis. 2nd ed. Oxford (UK): Blackwell Scientific Publications. 216 p. ISBN 13: 9780632021765.

Ogden JG 3rd. 1966. Forest history of Ohio. I. Radiocarbon dates and pollen stratigraphy of Silver Lake, Logan County, Ohio. Ohio J Sci. 66(4):387-400. http://hdl.handle.net/1811/5200

[ODGS] Ohio Division of Geological Survey. 2006. Bedrock geologic map of Ohio. Columbus $(\mathrm{OH})$ : Ohio Department of Natural Resources, Division of Geological Survey. Map BG-1, scale 1:2,000,000, 1 sheet: color, accompanying 1 p. text.

Parmalee PW, Munson PJ, Guilday JE. 1978. The Pleistocene mammalian fauna of Harrodsburg Crevice, Monroe County, Indiana. NSS Bull. 40(2):64-75. A publication of the National Speleological Society. https:/caves.org/pub/journal/PDF/V40/v40n2-Parmalee.htm

Rumph PF. 1975. An osteology of the white-tailed deer Odocoileus virginianus [master's thesis]. [Auburn (AL)]: Auburn University. 248 p. http://hdl.handle.net/11200/48623

Spurlock LB, Prufer OH, Pigott T, editors. 2006. Caves and culture: 10,000 years of Ohio history. Kent $(\mathrm{OH})$ : Kent State University Press. 463 p. ISBN 13: 978-0873388658.
Taylor TN, Taylor EL, Krings M. 2009. Paleobotany: the biology and evolution of fossil plants. 2nd ed. New York (NY): Academic Press, an imprint of Elsevier. Chapter 1, [section on] palynology. ISBN 13: 9780123739728.

Toft CA, Wright TF. 2015. Parrots of the wild: a natural history of the world's most captivating birds. Oakland (CA): University of California Press. Chapter 7, populations of parrots: conservation and invasion biology; p. 217-260. ISBN 13: 9780520239258.

Velhagen WA, Roth VL. 1997. Scaling of the mandible in squirrels. J Morphol. 232(2):107-132.

h t t p s:// d o i.org/10.1002/( S I C I ) 1097 4687(199705)232:2<107::AID-JMOR1>3.0.CO;2-7

Weeks JL, Tori GM, Sheildcastle MC. 1990. Coyotes (Canis latrans) in Ohio. Ohio J Sci. 90(5):142-145. http://hdl.handle.net/1811/23411

Werner JJ, Willoughby PR. 2018. Middle stone age point technology: blind-testing the damage distribution method. J Archaeol Sci. 19:138-147.

https://doi.org/10.1016/j.jasrep.2018.02.029 